\title{
Compositional Tuning of Ultrathin Surface Oxides on Metal and Alloy Substrates Using Photons: Dynamic Simulations and Experiments
}

\section{Citation}

Chang, Chia-Lin, Subramanian K. R. S. Sankaranarayanan, Dmitry Ruzmetov, Mark H. Engelhard, Efthimios Kaxiras, and Shriram Ramanathan. 2010. "Compositional Tuning of Ultrathin Surface Oxides on Metal and Alloy Substrates Using Photons: Dynamic Simulations and Experiments." Physical Review B 81 (8): 085406.

\section{Published Version}

doi:10.1103/PhysRevB.81.085406

\section{Permanent link}

http://nrs.harvard.edu/urn-3:HUL.InstRepos:13479090

\section{Terms of Use}

This article was downloaded from Harvard University's DASH repository, and is made available under the terms and conditions applicable to Other Posted Material, as set forth at http:// nrs.harvard.edu/urn-3:HUL.InstRepos:dash.current.terms-of-use\#LAA

\section{Share Your Story}

The Harvard community has made this article openly available.

Please share how this access benefits you. Submit a story.

Accessibility 


\title{
Compositional tuning of ultrathin surface oxides on metal and alloy substrates using photons: Dynamic simulations and experiments
}

\author{
Chia-Lin Chang, ${ }^{1}$ Subramanian K. R. S. Sankaranarayanan, ${ }^{1}$ Dmitry Ruzmetov, ${ }^{1}$ Mark H. Engelhard, ${ }^{2}$ \\ Efthimios Kaxiras, ${ }^{1,3}$ and Shriram Ramanathan $1, *$ \\ ${ }^{1}$ Harvard School of Engineering and Applied Sciences, Harvard University, Cambridge, Massachusetts 02138, USA \\ ${ }^{2}$ W.R. Wiley Environmental Molecular Sciences Laboratory, Pacific Northwest National Laboratory, Richland, Washington 99352, USA \\ ${ }^{3}$ Department of Physics, Harvard University, Cambridge, Massachusetts 02138, USA \\ (Received 13 October 2009; revised manuscript received 6 December 2009; published 2 February 2010)
}

\begin{abstract}
We report on the ability to modify the structure and composition of ultrathin oxides grown on $\mathrm{Ni}$ and $\mathrm{Ni}-\mathrm{Al}$ alloy surfaces at room temperature utilizing photon illumination. We find that the nickel-oxide formation is enhanced in the case of oxidation under photo-excitation. The enhanced oxidation kinetics of nickel in 5\% $\mathrm{Ni}-\mathrm{Al}$ alloy is corroborated by experimental and simulation studies of natural and photon-assisted oxide growth on pure $\mathrm{Ni}(100)$ surfaces. In case of pure Ni substrates, combined x-ray photoelectron spectroscopy analysis, and atomic force microscope current mapping support the deterministic role of the structure of nickel passiveoxide films on their nanoscale corrosion resistance. Atomistic simulations involving dynamic charge transfer predict that the applied electric field overcomes the activation-energy barrier for ionic migration, leading to enhanced oxygen incorporation into the oxide, enabling us to tune the mixed-oxide composition at atomic length scales. Atomic scale control of ultrathin oxide structure and morphology in the case of pure substrates as well as compositional tuning of complex oxide in the case of alloys leads to excellent passivity as verified from potentiodynamic polarization experiments.
\end{abstract}

DOI: 10.1103/PhysRevB.81.085406

\section{INTRODUCTION}

Metal alloys, which are ubiquitous in technological applications, typically are covered by a thin oxide layer which controls many of their properties and thus determines their usefulness. Changes in the properties of this oxide layer can dramatically alter the performance and functionality of the alloy material. $\mathrm{Ni}-\mathrm{Al}$ alloys are a representative example of metal-alloy materials with critical properties for a variety of technological applications. Oxide films formed on $\mathrm{Ni}-\mathrm{Al}$ alloy substrates are used as tunneling barriers in electronic devices, as templates for model catalysts and as passivation layers to protect against corrosion. ${ }^{1}$ They are utilized as coatings for several high-temperature applications because of their very good resistance to oxidation and corrosion, good thermal conductivity, and low density. ${ }^{2}$ These applications require precise control of the oxide structure, composition, and quality. ${ }^{3}$

Oxidation of $\mathrm{Ni}-\mathrm{Al}$ alloys can result in a complex mixture of $\mathrm{Al}_{2} \mathrm{O}_{3}, \mathrm{NiO}$, and $\mathrm{NiAl}_{2} \mathrm{O}_{4}$ oxides. ${ }^{4}$ The structure and composition of this oxide layer depends on the alloy composition, the oxygen pressure, and the oxidation temperature. For natural oxidation at low temperatures, the oxide layer formed on Ni-Al alloys is almost entirely composed of $\mathrm{Al}_{2} \mathrm{O}_{3} \cdot{ }^{5} \mathrm{In}-$ corporation of $\mathrm{NiO}$ into $\mathrm{Al}_{2} \mathrm{O}_{3}$ to form mixed oxides at low temperatures represents a significant challenge which has not been addressed to date. In particular, controlling the composition of binary oxides is extremely difficult due to microstructural changes brought about by phenomena such as surface segregation and micromixing of dopants. ${ }^{6}$ Furthermore, differences in the oxidation kinetics of the alloy constituents results in the formation of an oxide layer that is almost entirely composed of the constituent having higher oxidation rate. ${ }^{7}$ Similarly, there exists a critical composition of alloy (often equimolar) for which oxidation results in the forma-
PACS number(s): 81.65.Mq, 68.47.Gh, 81.05.Bx, 82.20.Wt

tion of mixed oxides. ${ }^{8}$ Phase stability of the binary oxides is another issue which limits the compositional tuning to high temperatures. ${ }^{9,10}$ Given these complexities, low-temperature compositional tuning at the atomic scale, especially for low dopant concentrations, is very difficult. Moreover, there is very limited understanding of the microscopic processes which can enable tuning of the composition of binary oxides grown on alloy substrates at low temperatures.

Recent experimental and theoretical investigations on oxide films grown under the influence of electric fields as well as under photon exposures have shown that dramatic differences exist in the oxide microstructure compared to films synthesized naturally. ${ }^{11-13}$ Interaction of UV photons with molecular oxygen leads to the creation of activated atomic oxygen and helps overcome the activation barrier for chemisorption. ${ }^{14}$ Additionally, the ionic currents within the growing oxide film are also enhanced by light-induced highfield migration. ${ }^{15}$ These photon-induced effects allow us to tune the composition of oxides grown on alloy substrates at room temperature and at the atomic level. While lowtemperature oxidation of pure metal surfaces such as $\mathrm{Al}(100)$ have been studied, the oxidation process in metallic compounds such as Ni-Al binary alloys is less clear, even though the latter is of great practical importance. ${ }^{1}$ Obtaining insights on a molecular level into the processes occurring in these complex systems becomes even more difficult, especially in the case of electron-stimulated oxidation and photon-assisted oxide synthesis.

There are several unanswered fundamental questions concerning the origin of microstructural and compositional changes in binary oxides, in the case of field-assisted oxidation, that lead to significant improvement in oxide properties grown on alloy substrates. Here, we report experimental observations (spectroscopic as well as electrochemical measurements) and atomistic simulation results on the ability to 
tune Ni-Al binary-oxide composition under athermal photon activation and we show that this ability is of tremendous importance in enhancing the passivation quality of oxide films grown on Ni-Al surfaces. Specifically, we report experimental results and variable-charge molecular-dynamics simulation studies investigating the ultrathin oxide growth on $5 \% \mathrm{Ni}-\mathrm{Al}$ alloy under the influence of photon-assisted oxidation. The atomic scale mechanism leading to compositional differences in the binary oxide that exist between natural and field-assisted oxidation is elucidated from the molecular-dynamics simulations. The effect of enhanced oxidation kinetics in photon-assisted oxide growth on pure $\mathrm{Ni}$ surfaces is also shown and compared with that obtained for native nickel oxide. The structural and morphological differences in the growing oxide film are evaluated using dynamical correlation functions.

To elucidate the role of enhanced oxidation kinetics of $\mathrm{Ni}$ on the composition of oxide scale grown on alloy substrates, we make systematic comparisons of experimental and simulation data for oxides formed on alloy substrates with those obtained in the case of pure $\mathrm{Ni}$ and $\mathrm{Al}$ substrates. The chemical state of the oxide constituents is characterized using x-ray photoelectron spectroscopy (XPS) and near-edge x-ray absorption fine structure spectroscopy (NEXAFS). Details of the experimental methods and analysis are presented in the subsequent sections. The evolution of charges and the atomic diffusivities for oxidizing conditions under varying electric fields in our simulations are used to explain the experimentally observed differences in oxide composition and the quality of the grown oxide film for the case of pure $\mathrm{Ni}$ and $\mathrm{Ni}-\mathrm{Al}$ alloy substrates.

\section{EXPERIMENTAL DETAILS}

\section{A. Sample synthesis}

Aluminum-nickel (Al-Ni) alloy thin films were deposited on ultralow-resistivity (100) silicon wafers by co-sputtering from an aluminum target and a nickel target. The composition ratio of nickel in these alloy thin films as verified by Rutherford backscattering spectroscopy was $\sim 5$ at. $\%$. The base pressure of the sputtering chamber was approximately 4E-9 Torr, and the thickness of these films was nearly 200 nm. Every silicon wafer, prior to $\mathrm{Al}-\mathrm{Ni}$ deposition, was dipped in dilute hydrofluoric acid for two minutes. It was then rinsed in deionized water and dried in nitrogen to remove the native oxide and enable optimum electrical contact between the Al-Ni film and substrate. Additionally, nickel thin films were deposited on ultralow-resistivity (100) silicon wafers by sputtering from a nickel target at a pressure of 6 mTorr of argon. Following Al-Ni and pure Ni deposition, the samples were transferred into the load lock for photoactivated oxidation. A UV photon source which is custom designed and built into a load lock was used to perform oxidation studies under controlled atmospheres and as a function of temperature. Photon exposures on the samples were performed for $120 \mathrm{~min}$ at room temperature in 1 atm high-purity oxygen. Natural oxidation (i.e., with no exposure to UV light) at room temperature and identical oxygen pressures and exposure times was also performed on control samples.
These samples were then subjected to anodic polarization measurements.

\section{B. Electrochemical characterization}

The electrochemical corrosion test cell was filled with 0.5 $\mathrm{M} \mathrm{NaCl}$ neutral solution and included three electrodes: a reference electrode (SCE), a counter electrode (graphite rod), and a working electrode (WE, Ni thin film on silicon wafer and Al-Ni thin film on silicon wafer). Prior to electrochemical impedance spectroscopy (EIS) measurements, Porthole ${ }^{\mathrm{TM}}$ was attached on each sample for an exact $3 \mathrm{~cm}^{2}$ circular opening to face the $0.5-\mathrm{M} \mathrm{NaCl}$ solution electrolyte. Before the measurements were taken, the electrolyte was deaerated in $99.99 \%$ nitrogen gas for $1 \mathrm{~h}$. To minimize the effect of native $\mathrm{SiO}_{2}$ on the electrical connection of the working electrode, any undeposited area $\left(1 \mathrm{~cm}^{2}\right.$ on the edge of each sample) was cleaned with dilute HF (50:1) and deionized water.

EIS spectra on multiple samples were acquired at opencircuit potential to minimize the effect of chemistry on the oxide film in the solution using a Solartron EIS system in the frequency range of $100 \mathrm{kHz}$ to $0.01 \mathrm{~Hz}$. The amplitude of the applied alternating current potential was $5 \mathrm{mV}$ for all measurements. All measurements were performed on multiple samples to ensure reproducible results. Tafel analysis was performed to obtain linear-polarization measurements for each sample after the EIS measurements. A scan rate of 1 $\mathrm{mV} / \mathrm{s}$ was adopted for the potential applied to the test electrode.

\section{X-ray photoelectron spectroscopy}

XPS was performed on various samples including 2-hnatural $\mathrm{Ni}, 2-\mathrm{h}-\mathrm{UV} \mathrm{Ni}, 2-\mathrm{h}-$ natural $\mathrm{Al}-\mathrm{Ni}$, and 2-h-UV Al-Ni to investigate the oxidation state of these thin films. The XPS experiments were performed using Physical Electronics Quantum 2000 Scanning ESCA Microprobe. This system uses a focused monochromatic aluminum $K \alpha$ x-ray (1486.7 $\mathrm{eV})$ source and a spherical section analyzer. The $\mathrm{x}$-ray beam used was a $100 \mathrm{~W}, 100-\mu \mathrm{m}$ diameter beam 4rastered over a $1.3 \times 0.2 \mathrm{~mm}^{2}$ area on the sample. Wide scan data were collected using pass energy of $117.4 \mathrm{eV}$. For the $\mathrm{Ag} 3 d_{5 / 2}$ line, these conditions produce a full width at half maximum (FWHM) of $1.6 \mathrm{eV}$. High-energy photoemission spectra were collected using pass energy of $46.95 \mathrm{eV}$. For the $\mathrm{Ag} 3 d_{5 / 2}$ line, these conditions produced a FWHM of $0.98 \mathrm{eV}$. The binding-energy scale was calibrated using $\mathrm{Cu} 2 p_{3 / 2}$ at $932.62 \pm 0.05 \mathrm{eV}$ and $\mathrm{Au} 4 f$ at $83.96 \pm 0.05 \mathrm{eV}$.

\section{Photon source}

The choice of light source is an important factor determining the effectiveness of a photochemical change in gas molecules as well as photon-assisted film synthesis. ${ }^{16}$ To take advantage of the photochemical reactions leading to $\mathrm{O}_{2}$ dissociation, a widely used light source for oxygen photochemistry is the low pressure $(<0.1$ Torr) mercury lamp (185 and $254 \mathrm{~nm}$ ). The use of UV range photons is an attractive option to create active oxygen species such as oxygen radicals and 


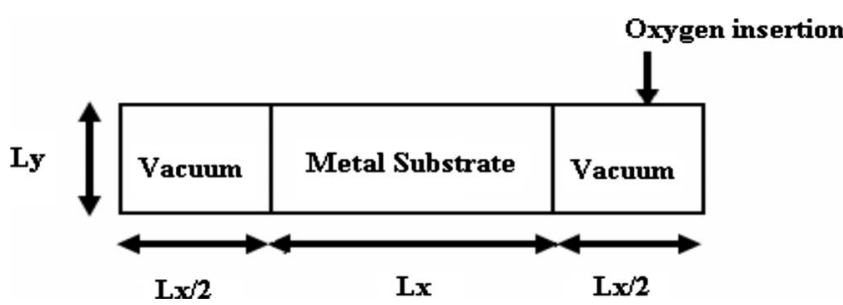

FIG. 1. Schematic showing the unit cell of alloy substrate and the vacuum slabs surrounding it.

has been used in this study. The $185 \mathrm{~nm}$ line is absorbed by oxygen molecules, forming ozone through dissociation. In addition, the $254 \mathrm{~nm}$ line rapidly decomposes $\mathrm{O}_{3}$ into molecular oxygen $\left(\mathrm{O}_{2}\right)$ and atomic oxygen. ${ }^{16}$ In the current work, the intensity at $254 \mathrm{~nm}$ for a $4 \times 4$ Grid Lamp located at $5 \mathrm{~cm}$ distance corresponds to $\sim 17 \mathrm{~mW} / \mathrm{cm}^{2}$. The intensity at $254 \mathrm{~nm}$ line is typically about $4-10$ times that at 185 $\mathrm{nm}$ line. The available literature data suggest that electric field strength generated could be in the range of 1-10 $\mathrm{MV} / \mathrm{cm}$ (Refs. 15 and 17-19) for the range of photon intensities typically employed in experimental studies. Therefore, a typical value of electric field, i.e., $10 \mathrm{MV} / \mathrm{cm}$ was utilized in the theoretical model used in this work.

\section{COMPUTATIONAL DETAILS}

\section{Molecular dynamic (MD) simulations of electric field assisted oxidation}

We first report MD simulations of oxidation and oxide growth on $\mathrm{Ni}(100)$ surfaces for the case of natural- and photon-assisted-oxide synthesis. These simulations were then extended to model the oxide growth on the surface of $\mathrm{Ni}-\mathrm{Al}$ alloy. The setup of the oxidation simulations is as follows: a slab of fcc $\mathrm{Ni}$ with dimensions $\left(1 \times 3.5 \times 3.5 \mathrm{~nm}^{3}\right)$ was formed from a fcc unit cell. The surfaces were generated by artificially increasing the $x$ direction and introducing two vacuum slabs on each side of the metal substrate. This unit cell was repeated infinitely though three-dimensional space by applying periodic boundary conditions (Fig. 1). This configuration allowed for accurate computation of the Coulomb interaction by the Ewald summation technique. ${ }^{20}$ Similarly, a slab of fcc Ni-Al was generated for simulating alloy oxidation. In the case of Ni-Al substrate, the minimum-energy configurations are first obtained using the Monte Carlo simulations which are then thermalized in the $0-300 \mathrm{~K}$ temperature range by cooling and heating in steps of $20 \mathrm{~K}$. Each MD simulation comprised of 1000 equilibration steps ignoring the dynamic charge transfer between the metal atoms. The temperature was maintained constant at $300 \mathrm{~K}$ using a NoseHoover thermostat. ${ }^{21}$ The surfaces are allowed to freely relax during these equilibration runs. The equilibrated samples are then simulated in a NVT ensemble for 1 ps with dynamic charge transfer using the modified charge-transfer ionic potential model to generate the final $300 \mathrm{~K}$ relaxed configuration. The atomic charges in the alloy-metal samples were found to fluctuate around zero with a magnitude of $\pm 0.06 e$ at the outermost layers and $\pm 0.02 e$ in the bulk alloy.
After these equilibration runs, we start to oxidize the metal substrate. The oxidation of the metal and alloy substrates is initiated by introducing either $\mathrm{O}_{2}$ molecules for the case of natural oxidation or atomic oxygen $\mathrm{O}$ for the case of photon-assisted oxidation in the vacuum slab (Fig. 1). The $x$, $y$, and $z$ positions of the $\mathrm{O}$ or $\mathrm{O}_{2}$ molecules are chosen randomly. The oxygen number density is maintained constant at approximately $0.004 / \AA^{3}$ in all the cases. The velocities of the $\mathrm{O}$ and $\mathrm{O}_{2}$ are chosen from a Maxwell-Boltzmann distribution corresponding to the required temperature. Additionally, reflecting boundary conditions are imposed to the molecules/atoms that might reach the simulation box limit. The gas pressure is maintained constant during the simulation by introducing a new $\mathrm{O}_{2}$ molecule only when a molecule dissociates and forms bonds with the metal atoms. Similar procedure is applied in case of atomic oxidation as well. The equations of motion are integrated using a leapfrog scheme with time steps of $1 \mathrm{fs}{ }^{22}$ The charge-relaxation procedure used to minimize the electrostatic energy subject to the electroneutrality principle is very time consuming. Hence, the atomic charges were updated every tenth MD step. The influence of a more frequent charge update was found to have no influence on the observed simulation results.

\section{RESULTS AND DISCUSSION}

We first present experimental results on oxidation of pure $\mathrm{Ni}$ and Ni-Al for the case of natural- and photon-assistedoxide synthesis. The differences between the structure, morphology, and composition of the natural and photonsynthesized oxides formed on the metal and alloy substrates are analyzed using several different experimental techniques. Furthermore, we present results from the atomistic simulations which provide insights into the atomic-scale mechanisms leading to the significant differences observed experimentally.

\section{A. Anodic potentiodynamic polarization measurements}

\section{Pure nickel}

Anodic potentiodynamic polarization measurements performed on naturally and UV-oxidized nickel as well as the Bode plots in the frequency range between $10 \mathrm{kHz}$ and 10 $\mathrm{mHz}$ are shown in Fig. 2. The modified Randles equivalent circuit is adopted to fit the Bode plots and the corrosion resistance is 8304 and $80476 \Omega$ for naturally oxidized $\mathrm{Ni}$ and UV oxidized $\mathrm{Ni}$, respectively. Polarization measurement gives an indication of the conduction properties of the passive-oxide film. The open-circuit potential (OCP) as well as pitting potential are all shifted in the positive polarization direction in the case of UV oxidized Ni suggesting superior oxide-film stability. The OCP of naturally oxidized $\mathrm{Ni}$ is $\sim-0.53 V_{\mathrm{SCE}}$ (the potential measured on the basis of the saturated calomel electrode) which is similar to that of pure nickel as reported by other authors. ${ }^{23}$ Strikingly different corrosion behavior is seen in UV oxidized Ni. OCP of UV oxidized $\mathrm{Ni}$ is about $\sim+0.18 V_{\mathrm{SCE}}$ which is similar to that of anodically oxidized nickel in borate buffer solution. ${ }^{24}$ This implies that the passive-oxide film on UV oxidized Ni could 


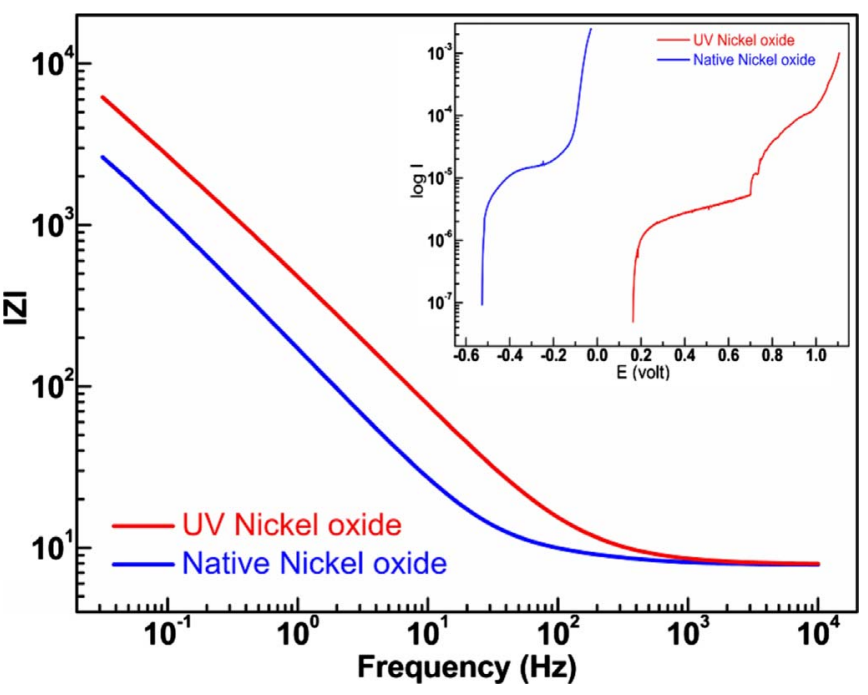

FIG. 2. (Color online) Bode diagrams for naturally and UVoxidized nickel in $0.5 \mathrm{M} \mathrm{NaCl}$ solution at room temperature. Inset shows their polarization curves with a scan rate of $1 \mathrm{mV} / \mathrm{s}$ in the same solution.

be nearly $\mathrm{NiO} / \mathrm{Ni}_{2} \mathrm{O}_{3} / \mathrm{Ni}(\mathrm{OH})_{2}$ and therefore undergoes the similar redox reactions resulting in similar ionic and electronic conduction phenomena. Not only is the OCP shifted in the positive polarization direction to $+0.18 V_{\mathrm{SCE}}$ but the pit-
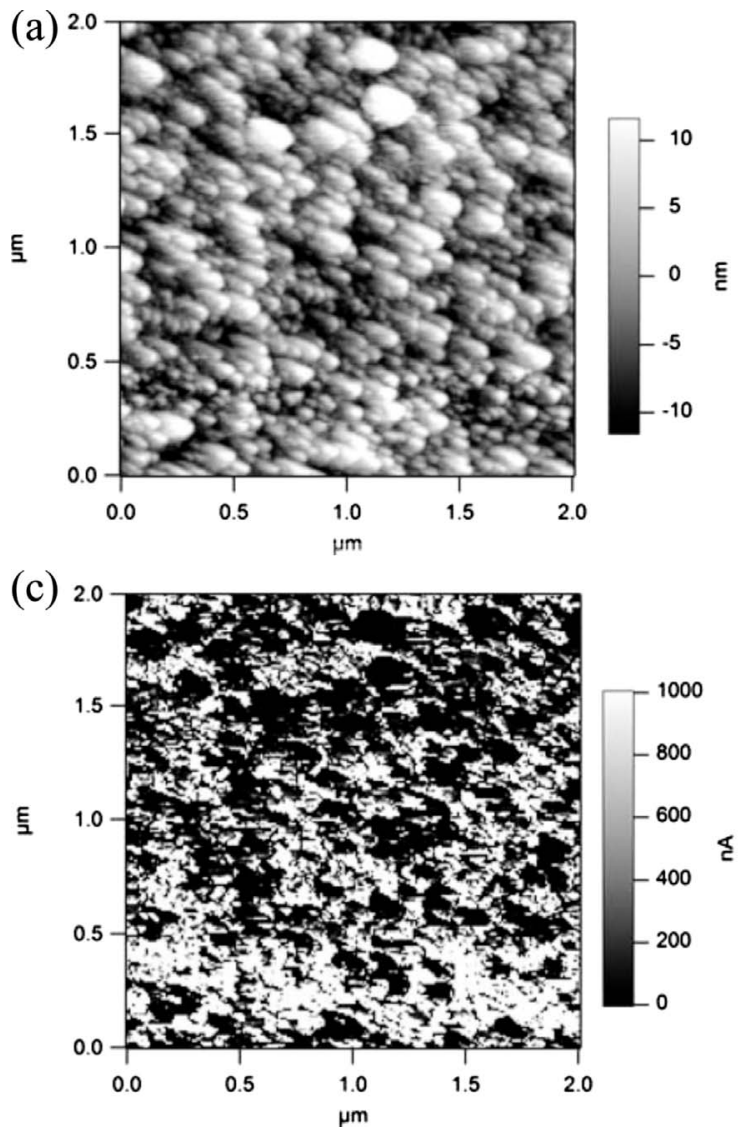

ting potential also shows a shift to $\sim+0.7 V_{\text {SCE }}$. Even in $0.5 \mathrm{M} \mathrm{NaCl}$ of our case, the pitting potential of UV oxidized $\mathrm{Ni}$ with the value of $+0.7 V_{\mathrm{SCE}}$ is higher than that of anodically oxidized nickel passive films $\left(\sim+0.4 V_{\mathrm{SCE}}\right)$ (Ref. 23$)$ in $0.35 \mathrm{M} \mathrm{NaCl}$. Passivity breakdown will be induced by $\mathrm{Cl}^{-}$at lower potentials as the $\mathrm{Cl}^{-}$concentration in the passive oxide increases. ${ }^{23}$ Oxidation of $\mathrm{Ni}$ to an insulating state, i.e., $\mathrm{NiO}$ in a complete $\mathrm{NiO} / \mathrm{Ni}(\mathrm{OH})_{2}$ structure would result in an increase in resistance to ionic- and electronic-conduction phenomena. This manifests itself in the form of increased corrosion resistance of the UV-synthesized nickel-oxide films.

We have also performed atomic force microscope (AFM) current mapping to support the deterministic role of the structure of nickel passive-oxide films on their nanoscale corrosion resistance. Figure 3 shows the topography and the corresponding current map for natural oxidation [Figs. 3(a) and 3(c)] and UV oxidation [Figs. 3(b) and 3(d)]. In the current map, the observed profiles (bright color) indicate large current densities. Their mean values are 7.8 and 2.25 $\mathrm{uA}$, respectively, for the two films. For naturally oxidized Ni, when the topography is paired with the current map, it appears that islandlike distribution exist for native nickel oxide. This nonuniform distribution increases the possibility of exposure of pure nickel to corrosive aqueous environment. Additionally, such discontinuities will induce higher adsorption of chloride ions on the edges which will lead to accelerated dissolution of the passive films. ${ }^{25,26}$
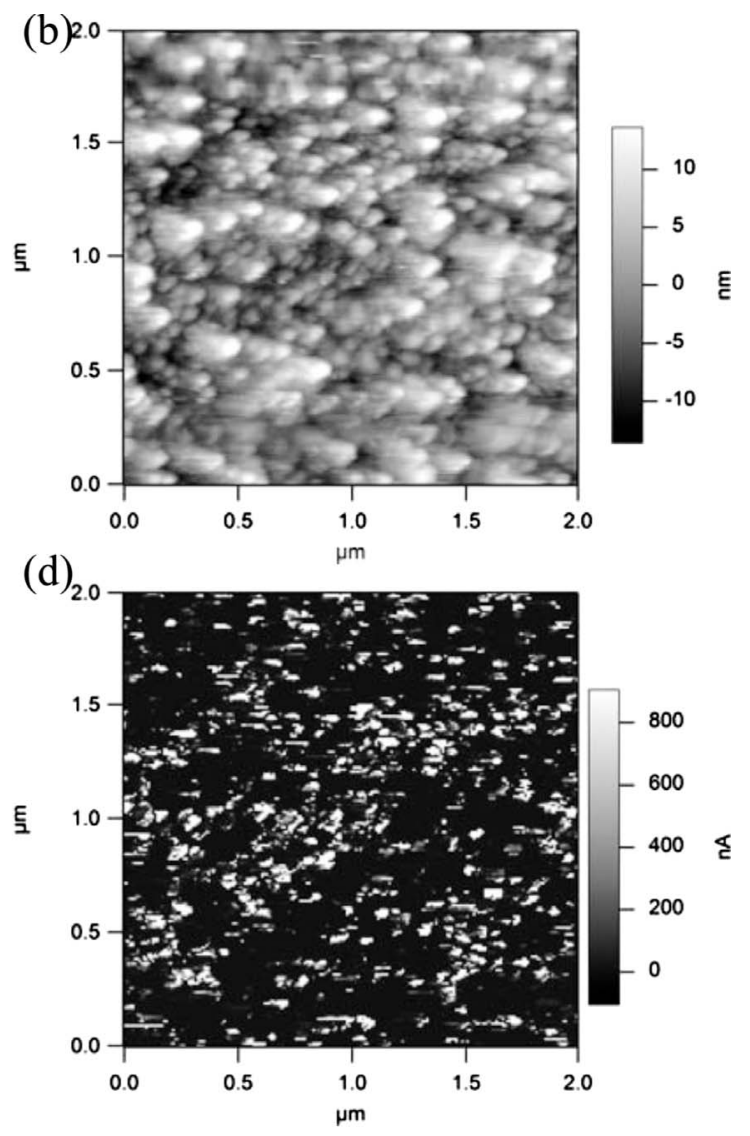

FIG. 3. AFM ORCA topography map (a) Naturally oxidized Ni, (b) UV oxidized Ni and their corresponding current map, (c) Naturally oxidized $\mathrm{Ni}$, and (d) UV oxidized Ni. Scan size is $2 \times 2 \mu \mathrm{m}^{2}$, a nanoneedle tip with spring constant of $3 \mathrm{~N} / \mathrm{m}$ and length of $1 \mu \mathrm{m}$ is used and applied voltage is $1 \mathrm{~V}$. 


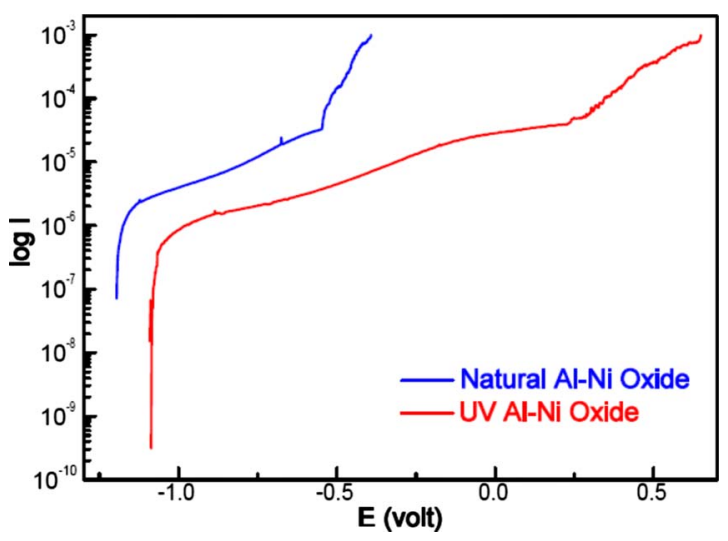

FIG. 4. (Color online) Polarization curves for 2-h naturally oxidized and 2-h UV-oxidized Al-Ni thin films in deaerated $0.5 \mathrm{M}$ $\mathrm{NaCl}$ solution at room temperature.

At room temperature, further oxidation process of nickel requires more extreme condition to proceed. In contrast to the islandlike distribution of nickel oxide in naturally oxidized $\mathrm{Ni}$, the possibility of a more continual oxide formation is reflected by the current map as seen in Fig. 3(d) for UV oxidized Ni. Larger grained structures in Fig. 3(b) with much lower current density as shown in Fig. 3(d) suggest the lateral growth of nickel oxides for UV-assisted synthesis. The current-density level as indicated in Fig. 3(d) shows an overall reduction across the grown oxide film. These results thus provide a correlation of current characteristics of passive film on nickel and its protective property against corrosive environments.

\section{Ni-Al alloy substrate}

Anodic potentiodynamic polarization measurements were similarly performed on naturally and UV-oxidized aluminum-nickel thin films as shown in Fig. 4. As discussed earlier, the polarization measurements give an indication of the conduction properties of the passive-oxide film. We find that the OCP as well as pitting potential are all shifted in the positive polarization direction in the case of 2-h UV-oxidized aluminum-nickel (Al-Ni) thin film suggesting superior oxide-film stability. The OCP of naturally oxidized Al-Ni thin film is about $\sim-1.4 V_{\mathrm{SCE}}$ which is identical to that for pure aluminum. ${ }^{27,28}$ This identical OCP implies that the native passive-oxide film on $\mathrm{Al}-\mathrm{Ni}$ should be nearly pure alumina and therefore undergoes the same redox reactions resulting in similar ionic- and electronic-conduction phenomena. The pitting potential of native $\mathrm{Al}-\mathrm{Ni}$ $\left(\sim-0.55 V_{\mathrm{SCE}}\right)$ is slightly higher than that of pure aluminum $\left(\sim-0.7 V_{\mathrm{SCE}}\right)$. We observe a strikingly different corrosion behavior in the case of UV-oxidized aluminum-nickel thin films. Not only is the OCP slightly shifted in the positive polarization direction to $-1.2 V_{\mathrm{SCE}}$ but the pitting potential is also greatly shifted to $\sim+0.5 V_{\mathrm{SCE}}$. Oxidation of $\mathrm{Ni}$ to an insulating state, i.e., $\mathrm{NiO}$ in the alloy oxide film would result in an increase in resistance to ionic- and electronicconduction phenomena. This manifests itself in the form of increased corrosion resistance of the UV-synthesized binaryoxide films.

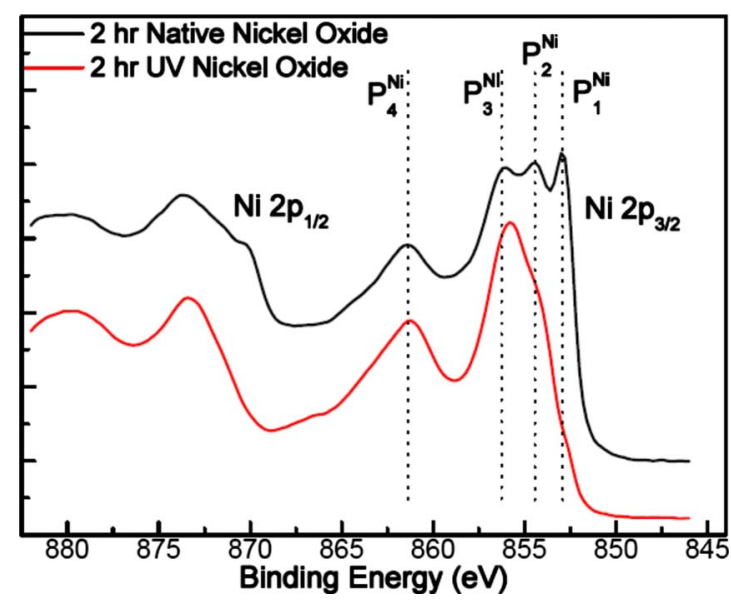

FIG. 5. (Color online) XPS spectra of Ni $2 p$ on as-received 2-h naturally oxidized and 2-h UV-oxidized pure $\mathrm{Ni}$ thin films.

\section{B. XPS analyses of passive-oxide film}

To investigate nickel-oxide formation during the UV oxidation of Ni-Al and its role in improving the corrosion resistance of passive-oxide film formed on $\mathrm{Ni}-\mathrm{Al}$ substrates, we first provide experimental information on the photon-assisted and natural oxidation of pure Ni. Detailed analysis of the spectra obtained from the oxide film formed in the case of pure $\mathrm{Ni}$ films and pure $\mathrm{Al}$ films and their comparison with that obtained for $\mathrm{Ni}-\mathrm{Al}$ substrates also helps establish $\mathrm{NiO}$ formation in photon-assisted oxide formed on $\mathrm{Ni}-\mathrm{Al}$ substrates.

\section{Pure nickel}

The Ni $2 p$ XPS of as-grown 2-h naturally and UVoxidized nickel thin films is shown in Fig. 5. The spectra can be divided into two edges split by spin-orbit coupling as $2 p_{1 / 2}(870-885 \mathrm{eV})$ and $2 p_{3 / 2}(846-869 \mathrm{eV})$. Three main peaks $\left(\mathrm{P}_{1}^{\mathrm{Ni}}, \mathrm{P}_{2}^{\mathrm{Ni}}, \mathrm{P}_{3}^{\mathrm{Ni}}\right)$ and one broad satellite peak $\left(\mathrm{P}_{4}^{\mathrm{Ni}}\right)$ are revealed in the Ni $2 p_{3 / 2}$ XPS spectra for 2-h naturally oxidized nickel thin film as seen in Fig. 5. Peak $\mathrm{P}_{1}^{\mathrm{Ni}}$ located at binding energy of $852.9 \mathrm{eV}$ is referred to $\mathrm{Ni}$ metal peak and shows comparable intensity to other peaks. $\mathrm{NiO}$ is a chargetransfer-type insulator as seen from electron spectroscopic valence-band studies. ${ }^{29}$ This model proposes that the hybridization of $\mathrm{Ni} 3 d$ and $\mathrm{O} 2 p$ orbitals gave $\mathrm{O} 2 p$ hole states lying inside the $d$ correlation gap. $\mathrm{Ni}^{2+}$ ground state in $\mathrm{NiO}$ is primarily $3 d^{8}$ in character. ${ }^{30,31}$ The broad satellite peak $\mathrm{P}_{4}^{\mathrm{Ni}}$ at binding energy of $861.1 \mathrm{eV}$, which is $\sim 7.0 \mathrm{eV}$ higher in binding energy than $\mathrm{P}_{2}^{\mathrm{Ni}}$, can be assigned for the final state as in electronic configuration forms of the unscreened $c 3 d^{8}$ (no ligand charge transfer) and the screened $\underline{c} 3 d^{10} \underline{L}^{2}$. The later screened final state was attributed to the intersite chargetransfer screening and the wider width has been attributed to oxygen banding effects. ${ }^{32}$

A small satellite structure, $\mathrm{P}_{3}^{\mathrm{Ni}}$, at $\sim 1.5 \mathrm{eV}$ binding energy of the main line $\mathrm{P}_{2}^{\mathrm{Ni}}$, is revealed in naturally oxidized nickel thin film. As seen in Fig. 5, a NiO matrix is revealed in the naturally oxidized nickel thin film since it contains $\mathrm{P}_{1}^{\mathrm{Ni}}$, $\mathrm{P}_{2}^{\mathrm{Ni}}$, and $\mathrm{P}_{3}^{\mathrm{Ni}}$ with comparable intensity. Strong metal line $\mathrm{P}_{1}^{\mathrm{Ni}}$ suggests that a major portion of nickel surface has not oxi- 
dized at room temperature. Indeed, the oxidation kinetics for nickel is significantly slow consistent with theoretical and experimental results. ${ }^{5,33}$

Significantly different spectrum is shown in UV-oxidized nickel thin film as seen in Fig. 5. Unlike the natural one, which has three comparable peaks within the binding-energy range from $850-858 \mathrm{eV}$, the spectra within the same bindingenergy range for UV-oxidized nickel thin film only shows a small bump. This hill can be composed of $\mathrm{P}_{2}^{\mathrm{Ni}}$, and $\mathrm{P}_{3}^{\mathrm{Ni}}$ with the same peak positions. Conventionally $\mathrm{P}_{3}^{\mathrm{Ni}}$ is considered to arise from contribution of trivalent nickel species $\left(\mathrm{Ni}^{3+}\right.$, excited $3 d$ states $^{34,35}$ having $3 d^{7}$ electron configuration) due to the deficient nickel oxide. ${ }^{31,36-38}$ But it can be assigned to $\mathrm{Ni}(\mathrm{OH})_{2}$ as well as in Refs. 39 and 40. We have performed the oxidation of pure $\mathrm{Ni}$ with and without the photon irradiation under 1 atm pure oxygen-gas pressure, but since the oxidation process is not carried out under controlled humidity, both trivalent oxidation state and hydroxyl nickel species are possible.

It is therefore possible to assign the three peaks to correspond to $\mathrm{Ni}, \mathrm{Ni}(+2)$, and $\mathrm{Ni}(+3)$ oxidation states for the case of native nickel oxide. The vanished or negligible metal line $\mathrm{P}_{1}^{\mathrm{Ni}}$ for UV oxidation in Fig. 5 suggests that the nickel metal surface is oxidized to form dense nickel oxide. Additionally, for the UV-oxidized film, we observe that the $\mathrm{Ni}(+3)$ peak is the most intense. Since this peak corresponds to the formation of $\mathrm{Ni}_{2} \mathrm{O}_{3}$, it appears plausible that the exposure to $\mathrm{UV}$ light induces the formation of the metastable $\mathrm{Ni}_{2} \mathrm{O}_{3}$ phase.

Based on the XPS profiles shown in Fig. 5, it is also possible that the naturally oxidized pure nickel thin film does not provide a uniform and complete stoichiometric monolayer oxide as revealed by the existence of comparable metal line $\mathrm{P}_{2}^{\mathrm{Ni}}$. It is, however, worth noting that the escape distance of the Ni $2 p$ photoelectrons is roughly $10-20 \AA$ for the photon-energy range studied here. Hence, the existence of unoxidized $\mathrm{Ni}$ in native oxide does not necessarily imply a nonuniform film. It is possible that the oxide film could be continuous but is thin enough for the unoxidized Ni substrate atoms to also be measured. Hence, the uniformity of naturally oxidized nickel thin-film oxide cannot be deduced from the XPS measurements alone shown in Fig. 5. To resolve this ambiguity and to further verify the atomic scale morphologies of the growing oxide islands, we have performed atomistic simulations to simulate the oxidation and oxide growth on Ni substrates, which is discussed in a subsequent section.

\section{Ni-Al alloy substrate}

To evaluate the photon-induced changes in the composition of oxide films grown on the aluminum-nickel alloy, several spectroscopic studies were carried out on identical samples. The Ni $2 p$ XPS spectra from both naturally and UV-grown samples are shown in Fig. 6. A single peak is revealed in the spin-orbit energy regions of $2 p_{1 / 2}(870-885$ $\mathrm{eV}$ ) and $2 p_{3 / 2}(846-869 \mathrm{eV})$, respectively. The Ni $2 p_{3 / 2}$ peak located at the binding energy of $852.9 \mathrm{eV}$ is assigned to nickel metallic phase which is present in the aluminumnickel alloy thin films as the solute element. The flat curve between the binding energy of 855 and $865 \mathrm{eV}$ suggests none or very little oxidized nickel solute (below the detectable

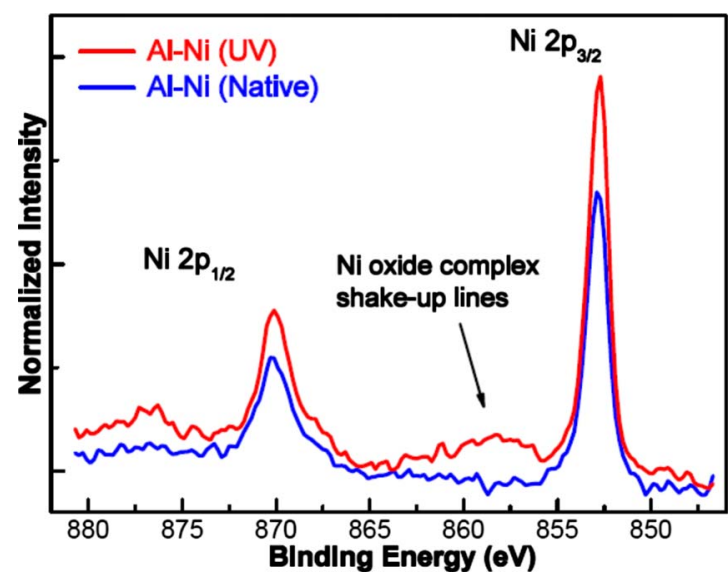

FIG. 6. (Color online) XPS spectra of Ni $2 p$ on as-received 2-h naturally oxidized and 2-h UV-oxidized Al-Ni thin films.

limit of XPS) in the native oxide film. Unlike naturally oxidized aluminum-nickel thin films, a broad satellite structure at binding energy ranging from 855 to $862 \mathrm{eV}$ in Fig. 6 is observed for UV-oxidized samples, which is attributed to the nickel-oxide-associated complex. Although there are certainly differences in the XPS spectra for UV-assisted and native oxides grown in $\mathrm{Ni}-\mathrm{Al}$ substrates, the broad satellite with relatively low intensity might not provide very clear information about the oxidized nickel in the passive-oxide barriers. However, we can state from a comparison of XPS spectra for pure $\mathrm{Ni}$ oxidation that the extent of $\mathrm{Ni}$ oxidizing in UV-assisted synthesis is significantly larger than that for natural oxidation. To further investigate the differences, we have analyzed the NEXAFS spectra which are discussed below.

\section{NEXAFS analyses of passive-oxide films formed on pure $\mathrm{Ni}$ and $\mathrm{Ni}-\mathrm{Al}$ alloy substrates}

We carried out x-ray absorption spectroscopy (XAS) studies on naturally oxidized pure aluminum, naturally and UVoxidized aluminum-nickel films as shown in Figs. 7-9. The XAS experiments were performed in Auger electron yield mode which is surface sensitive. The surface sensitivity of this method is related to the mean free path of $\mathrm{O}(K L L)$ Auger electrons in the range of 5-20 $\AA,{ }^{41}$ which is highly suited for the nanoscale oxide films used in our study. The spectrum of naturally oxidized pure aluminum thin film shows double band structure caused by the $\mathrm{O} 2 p$ states hybridized with $\mathrm{Al} 3 \mathrm{sp}$ states suggesting the existence of $\mathrm{Al}_{2} \mathrm{O}_{3}$. Such a spectrum is observed in naturally oxidized aluminum-nickel thin film confirming that the oxide film formed is primarily pure alumina.

The incorporation of oxidized nickel in the molecular structure of passive-oxide layers of aluminum nickel due to photon irradiation treatment is revealed from the NEXAFS $\mathrm{O} K$ edge spectra. For UV-oxidized aluminum-nickel thin films, a clear shoulder is present along with the $\mathrm{Al}_{2} \mathrm{O}_{3}$ associated double band structure. A transition-metal oxide such as nickel oxide can have up to four types of well-defined, partially occupied or unoccupied hybridized molecular orbit- 


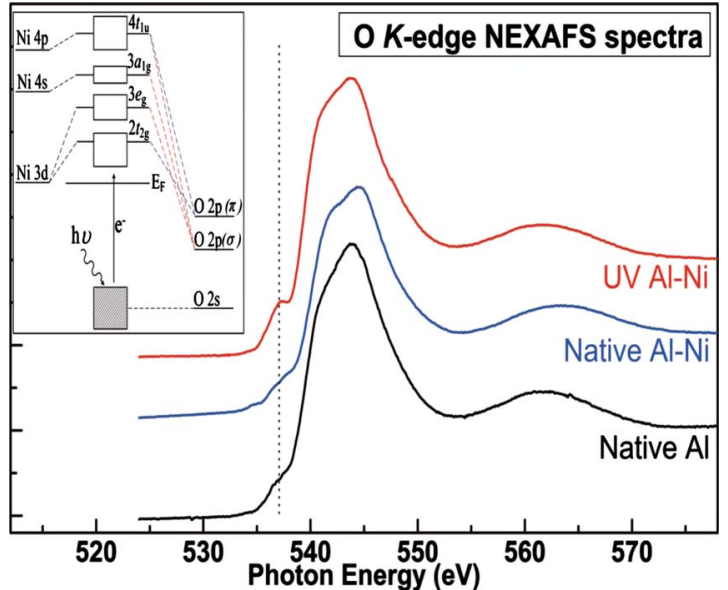

FIG. 7. (Color online) XAS spectra of 2-h naturally oxidized aluminum thin film, 2-h naturally oxidized Al-Ni thin film, and 2-h UV-oxidized Al-Ni thin film. The inset shows the oxide molecular orbitals which determine allowed electronic transitions.

als, depending on the number of $d$ electrons in the oxide. These hybridized molecular orbitals can be expressed in the qualitative order of energy levels ${ }^{41}$ and are shown as inset in Fig. 7

$$
\begin{aligned}
2 t_{2 \mathrm{~g}}(\mathrm{Ni} 3 d+\mathrm{O} 2 p \pi) & <3 e_{\mathrm{g}}(\mathrm{Ni} 3 d+\mathrm{O} 2 p \sigma) \\
& <3 a_{1 \mathrm{~g}}(\mathrm{Ni} 4 s+\mathrm{O} 2 p \sigma) \\
& <4 t_{1 \mathrm{u}}(\mathrm{Ni} 4 p+\mathrm{O} 2 p \pi) .
\end{aligned}
$$

The shoulder as indicated by the vertical dotted line revealed in UV-oxidized aluminum-nickel thin films can be assigned to electron transitions from $\mathrm{O} 1 s$ orbital to the $3 e_{\mathrm{g}}$ orbitals. The other two features resulting from the transition to $3 a_{1 \mathrm{~g}}$ and $4 t_{1 \mathrm{u}}$ orbitals are overlapped with the $\mathrm{Al}_{2} \mathrm{O}_{3}$ associated double band structure and hence the spectra cannot be distinguished. ${ }^{42}$

In the case of oxidation of pure Ni as shown in Fig. 8(a), the NEXAFS spectra of the four unoccupied hybridized orbitals are clearly observed. Consistent with the XPS spectra for pure $\mathrm{Ni}$ oxidation, we find that the extent of $\mathrm{Ni}$ oxidizing in UV-assisted synthesis is significantly larger than that for natural oxidation as evident from the peak at $537.1 \mathrm{eV}$. As brought out earlier, the spectrum of naturally oxidized pure

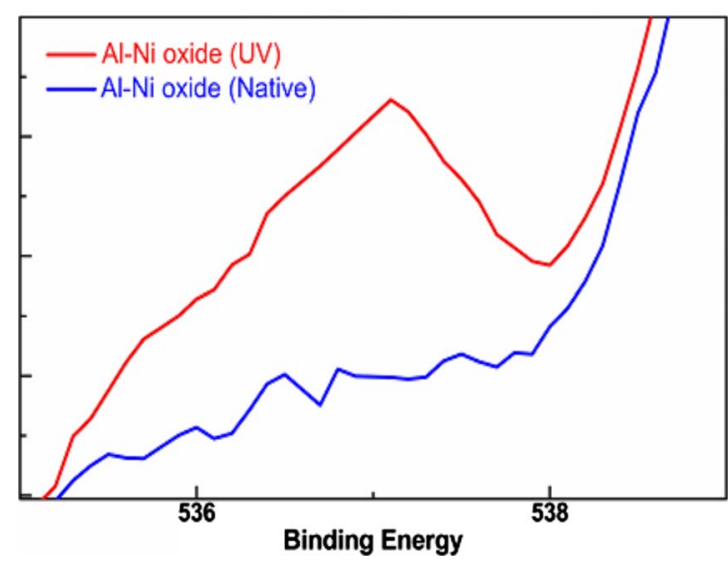

FIG. 9. (Color online) Enlarged XAS spectra showing Ni oxidation as a result of electron transitions from $\mathrm{O} 1 s$ orbital to the $3 e_{\mathrm{g}}$ orbitals.

aluminum thin film [Fig. 8(b)] shows double band structure caused by the $\mathrm{O} 2 p$ states hybridized with $\mathrm{Al} 3 s p$ states suggesting the existence of $\mathrm{Al}_{2} \mathrm{O}_{3}$. Such a spectrum is readily observed in both naturally and UV-oxidized pure $\mathrm{Al}$ as shown in Fig. 8(b). Furthermore, the naturally oxidized aluminum-nickel alloy thin film also exhibits a spectrum similar to that of pure $\mathrm{Al}_{2} \mathrm{O}_{3}$ in Fig. 8(b) confirming that the oxide film formed in naturally oxidized $\mathrm{Ni}-\mathrm{Al}$ is primarily composed of pure alumina [Fig. 8(c)]. On the other hand, for UV-oxidized aluminum-nickel thin films shown in Fig. 8(c), a clear shoulder at $537.1 \mathrm{eV}$ similar to that observed in pure $\mathrm{Ni}$ is present along with the $\mathrm{Al}_{2} \mathrm{O}_{3}$ associated double band structure. ${ }^{42}$ To further clearly show the differences in the UV-oxidized and naturally oxidized Al-Ni spectra, the enlarged spectra for naturally oxidized and UV-oxidized Al-Ni is shown in Fig. 9. These results indicate a change in the bonding characteristics due to $\mathrm{Ni}$ oxidation and its incorporation into the $\mathrm{Al}$ oxide passive film in the case of UV oxidation of Al-Ni. The combined XPS and O $K$-edge NEXAFS spectra thus confirm the existence of oxidized nickel in the UV-synthesized oxide.

\section{MD simulations of electric field assisted oxidation}

\section{Pure nickel substrate}

To simulate the structural and morphological features associated with early stages of oxide growth in the case of
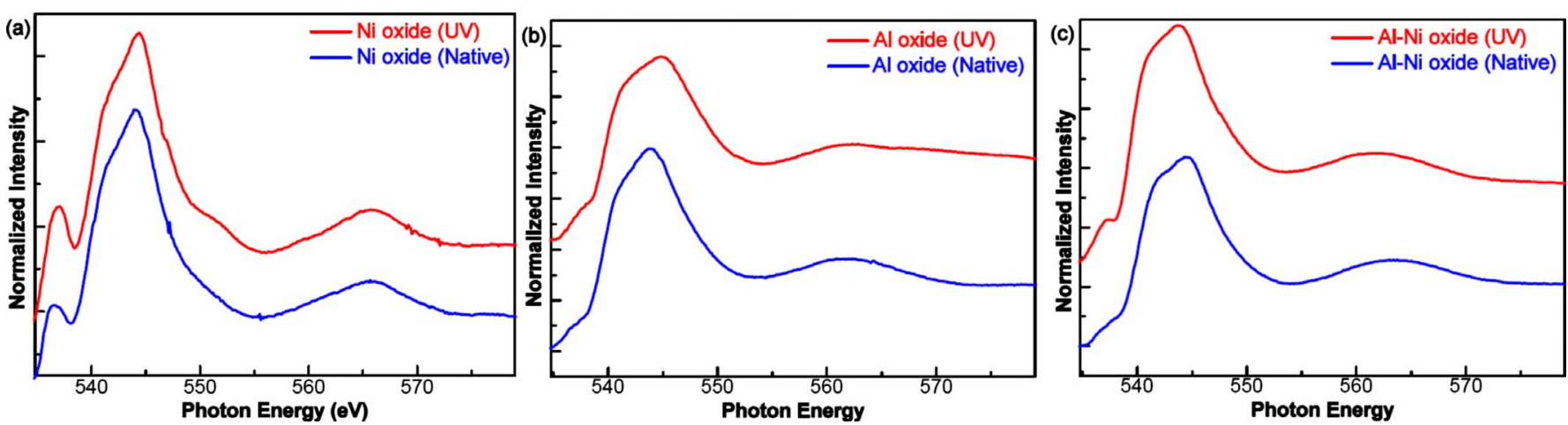

FIG. 8. (Color online) XAS spectra of 2-h naturally and UV oxidized (a) Nickel, (b) Aluminum, and (c) Al-Ni thin films. 




(a)

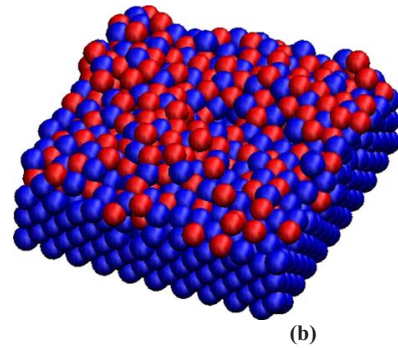

(b)
FIG. 10. (Color online) Snapshots showing simulated oxide growth on the surface of $\mathrm{Ni}(100)$ surface at room temperature for (a) natural and (b) photon-assisted oxidation. Oxygen atoms are shown in red (dark gray) and nickel atoms are shown in blue (lighter gray).

natural and UV-assisted oxidation, we utilize MD simulations which employ a potential model that allows for variable and dynamic charge transfer between atoms. ${ }^{43}$ This potential is capable of treating both metallic and ceramic systems as well as bond formation and bond breakage involved in oxidation processes. Additionally, it can take into account the presence of multiple oxidation states in the oxide film. UV photon interaction with molecular oxygen leads to the creation of activated atomic oxygen which can help overcome the activation barrier for chemisorption, leading to significantly increased rates of oxygen incorporation. ${ }^{14}$ Additionally, UV-light-induced high-field migration also enhances the ionic currents within the growing oxide film which comprises the electric field effect. ${ }^{15}$ These photon effects result in significantly increased oxidation kinetics which can lead to atomic scale structural and morphological differences when compared to native-oxide films.

Figure 10 shows the simulated oxide growth snapshots on $\mathrm{Ni}$ in the case of natural and photon-assisted oxidation. Atomistic observation of the growth process suggests formation of two-dimensional (2D) islands in case of natural oxidation which results in a nonuniform surface oxide whereas a more uniform oxygen distribution is observed for photonsynthesized oxide. We find that the calculated surface area coverage of the oxide scale in case of natural oxidation corresponds to approximately $55 \%$ whereas the same in case of photon-assisted oxide corresponds to approximately $90 \%$.

The oxide-growth characteristics on pure $\mathrm{Ni}$ surfaces were further explored using the calculated in-plane and outof-plane oxygen diffusion coefficients. The out-of-plane diffusion coefficients characterize the outward oxide growth whereas the in-plane diffusivity indicates the extent of uniformity of the oxide scale formed on the metal substrate. For initial exposure time less than $100 \mathrm{ps}$ in the case of natural oxidation, we observe that the out-of-plane diffusion coefficients are much higher than the in-plane diffusion coefficient. During this time, the $\mathrm{O}$ atoms are able to penetrate into the sublayer of the substrate and bond with the Ni atoms that are present in the second atomic layer. The oxidation of alloy surfaces thus creates 2D oxide islands in an atomic layer, while the metal islands exist in the previous atomic layer. This suggests that the initial oxidation of $\mathrm{Ni}(100)$ surface does not progress by the layer-by-layer process. Instead it is characterized by island formation which leads to nonuniform oxide distribution across the substrate surface. In contrast, the in-plane diffusion coefficients calculated for the oxide scale formed on pure $\mathrm{Ni}$ is higher than out-of-plane diffusion coefficient throughout the photon-assisted oxidation process. This is mainly attributed to the reduced activation-energy barrier $\left(\sim \frac{1}{2} q a E \approx 0.18 \mathrm{eV}\right)$ for ionic migration in photonassisted Ni oxidation. Thus in case of photon-assisted oxidation of pure $\mathrm{Ni}$, the growth and development of the oxide film proceeds in a layer-by-layer mode. The higher in-plane diffusion ensures that the $2 \mathrm{D}$ oxide growth in a particular atomic layer is completed before the growth front can proceed to the next atomic layer. This ensures that the oxide scale formed is more uniform than that for native oxide.

\section{Ni-Al substrate}

To further facilitate comparison with the experiments carried out on $\mathrm{Ni}-\mathrm{Al}$ substrates, we have simulated oxidation of $\mathrm{Ni}-\mathrm{Al}$ alloy containing $5 \% \mathrm{Ni}$. The initial minimum-energy configuration was generated using Monte Carlo simulations and consisted of a structure in which the Ni atoms segregate at the exposed faces. ${ }^{5}$ As mentioned earlier, the interaction of UV photons with molecular oxygen leads to the creation of activated atomic oxygen ${ }^{14}$ and enhancement of the ionic currents within the growing oxide film by light-induced highfield migration. ${ }^{15}$ Therefore, we study molecular and atomic oxidation of $5 \% \mathrm{Ni}-\mathrm{Al}$ substrates in the presence and absence of an external electric field. Oxidation kinetics enhancement due to externally applied electric field in case of metals such as $\mathrm{Al}$ is observed at electrostatic potentials approaching the Mott potential and higher. ${ }^{13}$ Typical values of electric field produced across the oxide film in electron-stimulated oxidation of Al by Popova et al. ${ }^{12}$ correspond to $10 \mathrm{MV} / \mathrm{cm}$. Similar fields are also produced in UV-assisted oxidation and hence an electric field of $10 \mathrm{MV} / \mathrm{cm}$ is used in these simulations to capture the effect of field-enhanced oxidation on the compositional changes associated with oxide growth on alloy substrates.

The oxide formed on $5 \% \mathrm{Ni}-\mathrm{Al}$ alloy is amorphous in nature for all the simulated cases. Figure 11 shows the partial pair-distribution function (PDF) of each type of atoms computed for pure $\mathrm{Ni}$ as well as the $5 \% \mathrm{Ni}-\mathrm{Al}$ alloy substrate. The Al-O PDF [Fig. 11(b)] shows a peak at around 1.7-1.9 $\AA$ for exposure times beyond $25 \mathrm{ps}$, that is, at the early stage of oxide nucleation. These distances correspond to the bond length reported for amorphous aluminum oxide, which ranges from $1.8-1.9 \AA .{ }^{44}$ For natural oxidation, the calculated Ni-O PDF for the $5 \% \mathrm{Ni}-\mathrm{Al}$ alloy does not show a sharp peak which indicates the absence of formation of nickel oxide at low temperatures. Experimentally reported bond lengths of $\mathrm{Ni}-\mathrm{O}$ by Caputi et al $^{45}$ are $\sim 1.94 \AA$. Hence, formation of nickel oxide should have resulted in a sharp peak in the Ni-O PDF at that distance as clearly seen in the PDF of oxide scale formed on pure Ni substrate as shown in Fig. 11(a). The native oxide scale is thus composed of $\mathrm{Al}_{2} \mathrm{O}_{3}$ consistent with our experimental results. Similar observations were also made by Jaeger et al. ${ }^{46}$ and Franchy et al. ${ }^{47}$ in their experimental studies of low-temperature oxygen adsorption on $\mathrm{Ni}-\mathrm{Al}(111)$ surfaces. In the case of atomic oxidation with and without externally applied electric field 


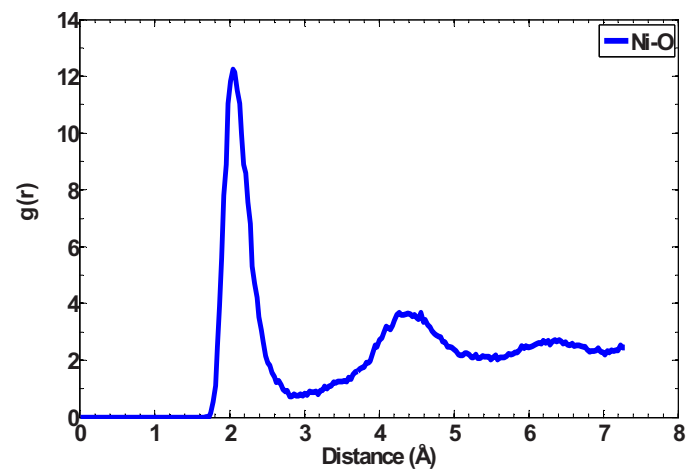

(a)

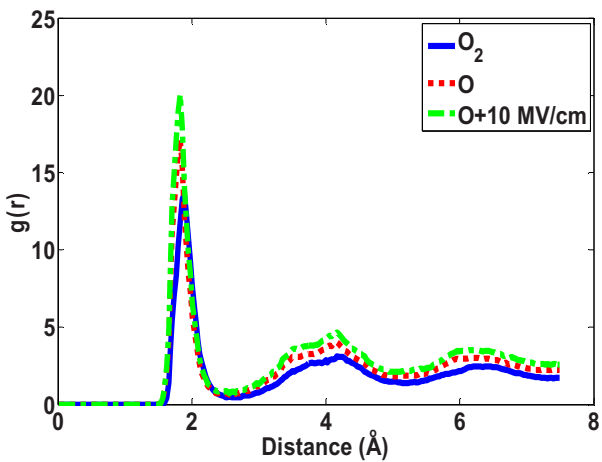

(b)

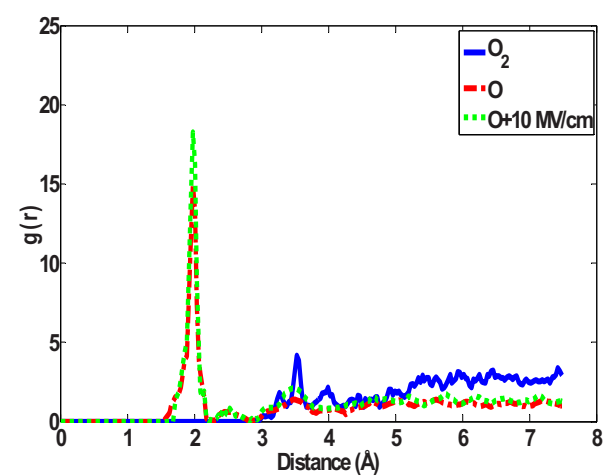

(c)

FIG. 11. (Color online) Pair-distribution function for: (a) native Ni-O in pure Ni system; (b) Al-O in $\mathrm{Al} / \mathrm{Ni} / \mathrm{O}$ system; and (c) Ni-O in $\mathrm{Al} / \mathrm{Ni} / \mathrm{O}$ system, taken at $100 \mathrm{ps}$ of exposure time.

(10 MV/cm), we note that the Ni-O PDF shows a peak at $\sim 2.0 \AA$ [Fig. 11(c)], which is suggestive of the formation of nickel oxide. These features are also observed in the experimentally obtained XPS and NEXAFS spectra.

We then analyzed the atomic charge distribution in the ultrathin oxide films (shown in Fig. 12). In the case of natural oxidation of the $\mathrm{Al}-\mathrm{Ni} / \mathrm{O}$ system, $\mathrm{Ni}$ atoms are weakly charged and do not assume full valence values. The charge transfer takes place primarily between the $\mathrm{O}$ atom and the nearest $\mathrm{Al}$ atoms. This suggests that the native oxide formed is almost entirely due to oxidation of aluminum atoms and corroborates the findings obtained experimentally and using the analysis of PDF. In the case of atomic oxidation with and without electric-field assisted oxidation of $5 \% \mathrm{Ni}-\mathrm{Al}$, a fraction of $\mathrm{Ni}$ atoms oxidize and attain charge value close to " $3+$ " at the oxide-gas interface and " $2+$ " when located at the interior and close to the metal-oxide interface. The $\mathrm{Ni}(3+)$ atoms appears to arise from the formation of metastable $\mathrm{Ni}_{2} \mathrm{O}_{3}$ and corroborates the experimental observations provided by XPS spectra. In the case of natural oxidation, although some charge appears to have been transferred from the nearest $\mathrm{Ni}$ atoms to the $\mathrm{O}$ atom (Fig. 12), our analysis indicates that the charge values of the $\mathrm{Ni}$ atom in the oxide interior fluctuates between 0 and $+1 e$. Although there appears to be a tendency on the part of $\mathrm{Ni}$ atoms to form oxide, the bond formed between oxygen and $\mathrm{Ni}$ does not appear to be stable. It is possible that the Ni-O bond formed is quickly replaced by the more stable Al-O bond. This argument is also supported by thermodynamic considerations. Comparison of the standard enthalpy of formation of the respective oxides,
$H_{f}(\mathrm{NiO})=-489.5 \mathrm{~kJ} / \mathrm{mol}$ and $H_{f}\left(\mathrm{Al}_{2} \mathrm{O}_{3}\right)=-1675.7 \mathrm{~kJ} / \mathrm{mol}$, suggests that it is more favorable to form Al-O bonds. ${ }^{48}$ This is manifested in the lack of nickel-oxide formation as shown by the pair distribution for the native oxide which was calculated by averaging over many such configurations.

\section{E. Calculation of activation energy}

The theory of oxidation kinetics in ultrathin films can be utilized in conjunction with the simulation data derived from the oxidation kinetic curves shown in Fig. 13 to get an estimate of the activation-energy barrier for oxidation on the $\mathrm{Ni}$-Al surfaces. The methodology adopted here is discussed in detail in our previous work and is summarized here. ${ }^{5}$ The general expression for the potential $(W)$ to be overcome in case of a field-assisted migration of an ion between two adjacent sites is given as ${ }^{49}$

$$
W=W_{0}-\frac{1}{2} q a E+\lambda L .
$$

In the above equation, $W_{0}$ represents the intrinsic barrier for ionic jumps between two positions in the oxide film, $q$ represents the charge on the ion, $2 a$ represents the jump length, $L$ is the oxide film thickness, and $\lambda$ is a term which depends on the oxide structure. The second term on the rhs represents the lowering of the energy barrier by an electric field $E$ across the oxide film, and the structure term $(\lambda)$ represents structural changes in the oxide film associated with the film growth. The oxidation kinetic curves shown in Fig. 13 can be fitted to a logarithmic growth curve which 

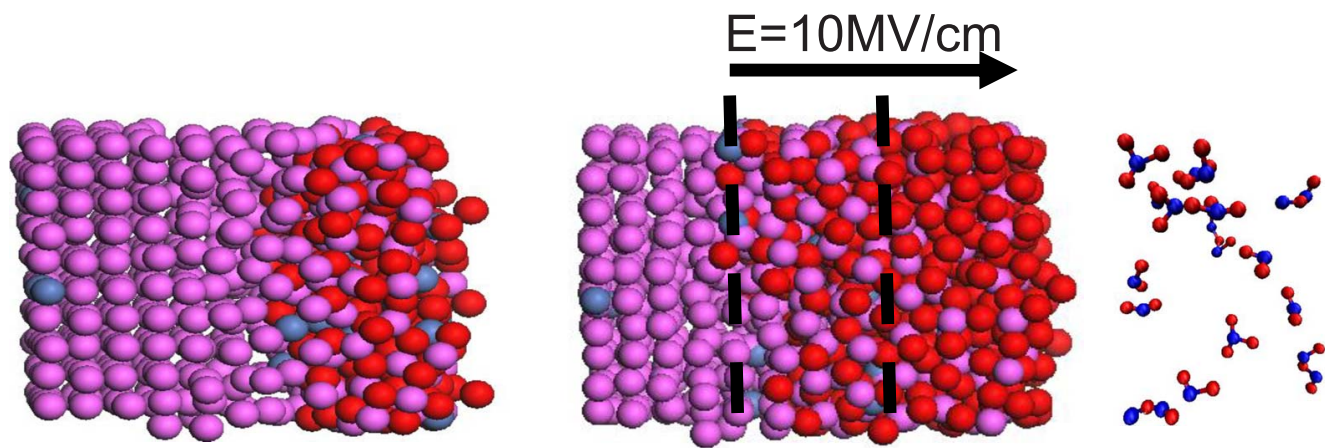

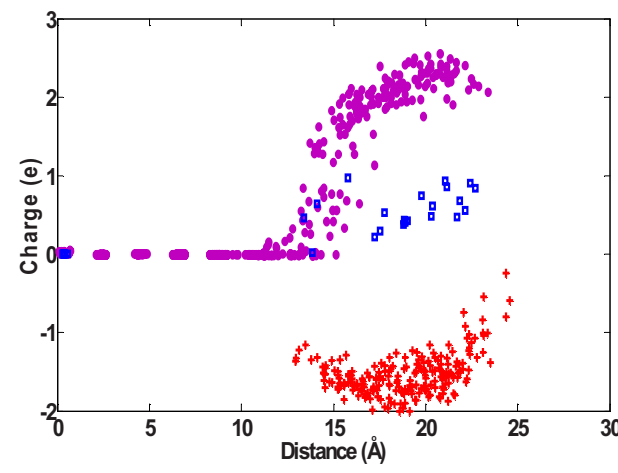

(a)

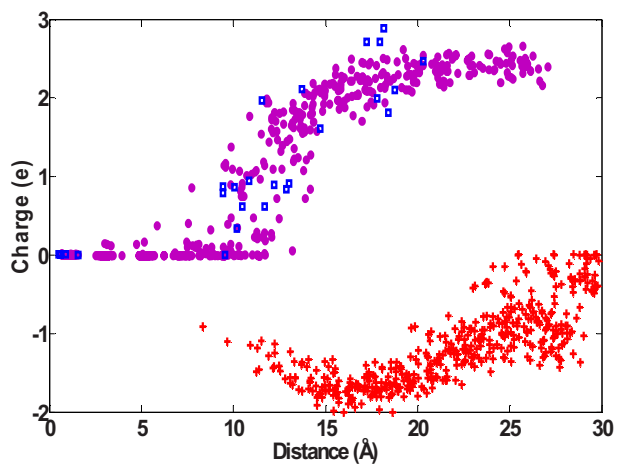

(b)

FIG. 12. (Color online) Charge distribution in $\mathrm{Al} / \mathrm{Ni} / \mathrm{O}$ systems with $5 \% \mathrm{Ni}$ taken at 100 ps of exposure time for: (a) oxidation by molecular oxygen and (b) oxidation by atomic oxygen in presence of $10 \mathrm{MV} / \mathrm{cm}$ electric field. The charge distribution is shown as charge of each atom versus its position in the sample. $\mathrm{Al}$ atoms are shown in purple, $\mathrm{O}$ in red and $\mathrm{Ni}$ in blue. The corresponding snapshots of the atomic arrangements in the oxidized sample are shown above each figure. Section of the snapshot for electric-field assisted oxidation is used to depict the Ni-O-Ni network.

allows us to deduce the activation-energy barrier for the three cases (molecular, atomic, and field-assisted oxidation, respectively). ${ }^{5}$

$$
\begin{aligned}
& C \exp \left(-\frac{W_{0}-\frac{1}{2} q a E}{k_{B} T}\right)=\exp \left(\frac{-697}{T}+1.69\right), \\
& C \exp \left(-\frac{W_{0}-\frac{1}{2} q a E}{k_{B} T}\right)=\exp \left(\frac{-760}{T}+2.77\right),
\end{aligned}
$$

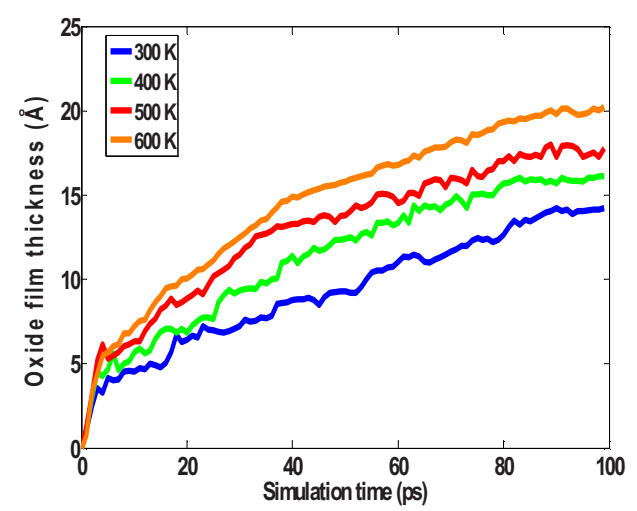

(a)

$$
C \exp \left(-\frac{W_{0}-\frac{1}{2} q a E}{k_{B} T}\right)=\exp \left(\frac{-930}{T}+2.59\right) .
$$

Using these Arrhenius fits shown in Eqs. (2)-(4), it is possible to get an estimate of the term $W_{0}-\frac{1}{2} q a E$. We find this to be $0.0801 \pm 0.01,0.0655 \pm 0.01$, and $0.0601 \pm 0.01 \mathrm{eV}$ for field-assisted, atomic, and natural oxidation, respectively. If the value of the electric field $E$ is known, then it is possible to get the exact estimate of the energy barrier $W_{0}$. The electric field lowers the energy barri-

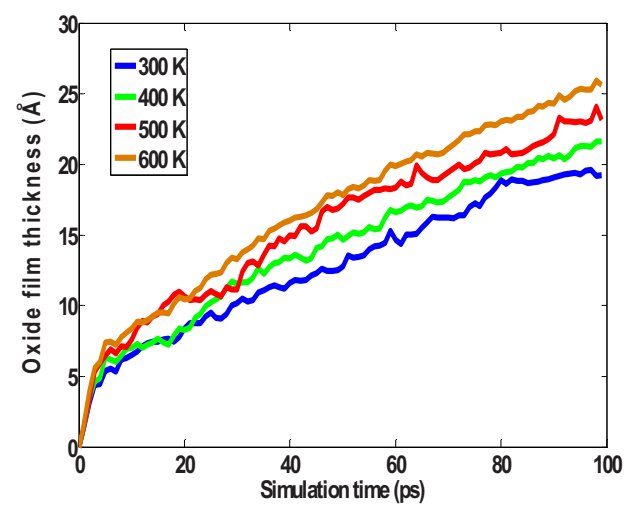

(b)

FIG. 13. (Color online) Oxidation kinetics curves of 5\% Ni-Al alloy surface at various temperatures (300-600 K) for (a) oxidation using molecular oxygen and (b) electric field assisted oxidation with atomic oxidation. 
TABLE I. Variation in the activation-energy barriers (in eV) for ionic migration in the growing oxide film.

\begin{tabular}{ll}
\hline \hline Oxidation & $\begin{array}{c}\text { Activation energy } \\
(\mathrm{eV})\end{array}$ \\
\hline Molecular oxidation & 0.49 \\
Atomic oxidation & 0.41 \\
Electric field+Atomic oxidation & 0.10 \\
\hline \hline
\end{tabular}

ers for the outward "hopping" of cations into and through interstices of the oxygen ion arrangement of the developing oxide film and is given by $E=V_{\mathrm{k}} / L$, where $V_{\mathrm{k}}$ represents the established potential and $L$ represents the thickness of the oxide film. Based on the low-temperature oxidation studies of aluminum by Jeurgens et al. ${ }^{50,51}$ it is possible to get an estimate of the established kinetic potential $\left(V_{\mathrm{k}} \sim 2 \mathrm{~V}\right)$. Additionally, in case of field-assisted oxidation, there is an externally applied electric field of $10 \mathrm{MV} / \mathrm{cm}$. In the present simulations, the self-limiting oxide-film thickness corresponding to field-assisted, atomic, and natural oxidation at room temperature corresponds to approximately 1.9, 1.6, and $1.4 \mathrm{~nm}$, respectively. Additionally, the average charge $q$ of the oxygen atoms in the oxide-film interior was found to be approximately $1.89 e, 1.82 e$, and $1.80 e$ for field assisted, $\mathrm{O}$, and $\mathrm{O}_{2}$ cases, respectively. The jump distance was approximated from the first-peak distance in the pair-distribution function for O-O $(\sim 3.1,3.1$, and $3.3 \AA$ for field-assisted, O and $\mathrm{O}_{2}$ cases, respectively). The computed activation-energy barriers are summarized in Table I.

\section{F. Oxygen incorporation into the ultrathin oxide films}

The rate of oxygen incorporation into the alloy oxide film can be evaluated using the mean-square displacement (MSD) for the $\mathrm{O}$ atoms located at the oxide-gas interface for the three cases (Fig. 14). In photon-assisted oxidation, the primary mechanisms for enhanced oxidation can be attributed to the presence of atomic oxygen and an electric field. Oxidation using atomic oxygen and/or in the presence of electric field leads to a significant increase in the oxygen diffusivity into the substrate. As brought out in the previous section, the

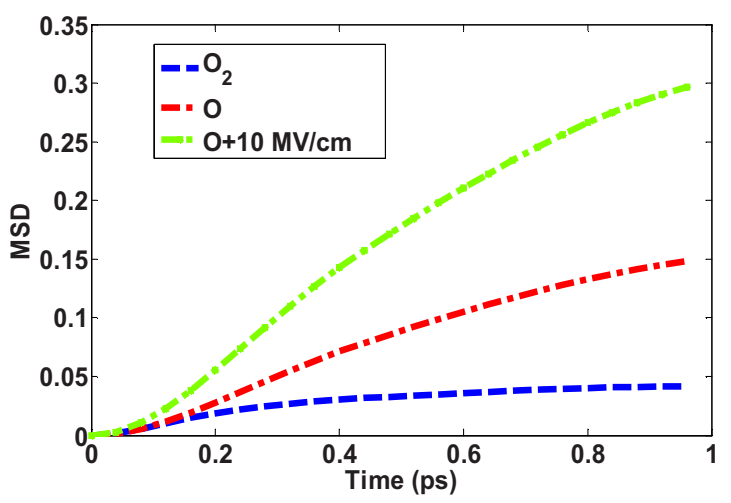

FIG. 14. (Color online) Calculated MSD at 50 ps of exposure time for $5 \% \mathrm{Ni}-\mathrm{Al}$ molecular oxidation, atomic oxidation with no field, and atomic oxidation with an external field of $10 \mathrm{MV} / \mathrm{cm}$. theory of oxidation kinetics in ultrathin oxide films in conjunction with the simulation data derived from the oxidation kinetic curves is used to get an estimate of the corresponding activation-energy barrier for ionic migration. Atomic oxidation eliminates the chemisorption barrier for oxygen dissociation at the surface and increases the rate of oxidation. The activation energy for ionic migration in case of atomic oxidation is $\sim 0.08 \mathrm{eV}$ lower than molecular oxidation. Likewise, increasing the electrostatic potential through the externally applied electric field leads to athermal stimulation of the ion diffusion, allowing for higher film growth rate than the saturation limit obtained using natural oxidation. ${ }^{12,13}$ For the applied field $(10 \mathrm{MV} / \mathrm{cm})$ across the film, a significant lowering of activation barriers for ionic diffusion at the metal-oxide and oxide-gas interfaces (shown in Fig. 14) is observed, even at temperatures which are otherwise insufficiently high for appreciable thermal diffusion of ions. ${ }^{13}$ In accordance with Cabrera-Mott theory for low-temperature oxidation, ${ }^{17}$ we find that the activation-energy barrier in the presence of external electric field is further lowered by $\sim 0.31 \mathrm{eV}$ in comparison to atomic oxidation: $\sim \frac{1}{2} q a E$ for oxygen migration; $q$ is the average charge of the oxygen atoms in the oxide film $(\sim-1.89 e), a$ represents the oxygen jump distance estimated from the first-peak distance in the pair-distribution function for $\mathrm{O}-\mathrm{O}(\sim 3.1 \AA)$ and $E$ is the applied electric field $10 \mathrm{MV} / \mathrm{cm}$. This explains the experimentally observed oxidation of $\mathrm{Ni}$ in the case of photonsynthesized oxides on $\mathrm{Ni}-\mathrm{Al}$ substrates.

\section{G. Corrosion resistance of ultrathin oxides}

The explanation for the enhanced corrosion resistance observed in case of photon-synthesized oxides on $\mathrm{Ni}-\mathrm{Al}$ may be provided on the basis of a recent graph theoretic approach proposed by McCafferty. ${ }^{3}$ According to this theory, a network of passivating $\mathrm{NiO}$ winds across the mixed oxide film providing increased corrosion resistance in case of binary alloys. Although the exact mechanism of increased corrosion resistance via incorporation of a network of passivating oxide in mixed oxides is not known, two scenarios arise. One possible explanation is that for binary alloys passivated by nickel, the Ni-O-Ni chains [shown in the sectional view in Fig. 14] are more stable in aqueous solution than the second component of the oxide film, i.e., Al-O. Comparison of polarization curves for passive oxides on pure Ni shown in Fig. 2 with that for pure $\mathrm{Al}$ substrate ${ }^{27}$ corroborate this. The other possibility suggested by $\mathrm{McCafferty}^{3}$ (related to the first) is that the tangled network of Ni-O-Ni chains in mixed oxides hinders the transport of halide ions and defects through the passive film. This could explain the experimentally observed higher pitting potential in case of UV-assisted passive oxide formed on Ni-Al alloy substrates (Fig. 4).

Kinetic effects play a major role in determining the composition and the microstructure of the resulting alloy oxide. ${ }^{52}$ Compared to natural oxidation, the rate of oxygen intake into the oxide film in photon-assisted growth is significantly increased due to an activation-barrier reduction. The enhanced oxidation kinetics due to elimination of the chemisorption barrier as well as lowered activation-energy barrier for ionic 
migration is responsible for the increased uptake of oxygen in the near-surface region of the passive-oxide film. ${ }^{13}$ For such increased oxide densities, it appears that there exists sufficient number of oxygen atoms to oxidize Ni. The oxygen species act as acceptors of electrons from the metal and hence generate more strong bonding chemisorption ions leading to $\mathrm{Ni}$ oxidation. The fraction of $\mathrm{Ni}$ atoms oxidized is therefore strongly correlated with the intake of oxygen atoms. In accordance with the proposed graph theory by McCafferty, ${ }^{3}$ the incorporation of this Ni-O-Ni network (Fig. 12) results in significantly enhanced corrosion resistance as seen in Fig. 4.

\section{CONCLUSIONS}

In summary, we have investigated the effect of photonassisted oxidation on the composition of ultrathin passiveoxide films grown on $\mathrm{Ni}-\mathrm{Al}$ alloy at room temperature. Oxidation in the presence of electric field such as that developed during photon-assisted synthesis can be used to tune the composition of binary $\mathrm{Ni}-\mathrm{Al}$ oxide at atomic length scales. Atomistic simulations indicate an increased rate of oxygen incorporation due to a reduced activation barrier for ionic migration in the presence of electric field, which provides sufficient oxygen species acting as electron acceptors from the metal and leads to Ni oxidation. These findings are corroborated by the oxidation states of such passive films studied by XPS and O $K$-edge XAS spectra.

The enhanced oxidation of nickel in the case of $\mathrm{Ni}-\mathrm{Al}$ alloy substrates is further substantiated by comparing the oxidation kinetics and oxide growth for naturally and photon-assisted oxidation of pure Ni substrates. For pure Ni oxidation, we show that photon-assisted nickel oxidation re- sults in a more uniform and continuous oxide-film growth which enables superior corrosion resistance. Both AFM current map and XPS analysis confirm the enhanced and uniform nickel oxide formation under the photon irradiation. Atomistic observation of the growth process and analysis of the dynamical correlation functions suggests an island growth mode in case of natural oxidation which results in a nonuniform surface oxide. The lowering of activation energy barrier in case of photon-assisted oxidation leads to faster oxidation kinetics and layer-by-layer growth resulting in a more uniform surface-oxide distribution. Our study on pure Ni oxidation provides an alternative approach to grow passive films on nickel instead of anodic oxidation in borate buffer $^{23,24}$ and acid sulfate ${ }^{53}$ solutions.

In the case of alloy substrates, our results suggest that tuning the composition of oxides by field-assisted oxidation can aid in the development of superior quality ultrathin alloy oxide films for a variety of technological applications including improved passivation layers for increased corrosion protection. In a broader context, our approach demonstrates a pathway to athermally tune oxygen concentration in nearsurface regions that is of great importance to contemporary problems in complex oxides.

\section{ACKNOWLEDGMENTS}

We thank the Office of Naval Research and the National Science Foundation for providing financial support for this work. XPS portion of the research was performed using EMSL, a national scientific user facility sponsored by the Department of Energy's Office of Biological and Environmental Research located at PNNL. The NEAFS experiments were performed at U12a, NSLS, sponsored by the U.S. Department of Energy.
*Corresponding author; shriram@deas.harvard.edu

${ }^{1}$ A. Stierle, F. Renner, R. Streitel, H. Dosch, W. Drube, and B. C. Cowie, Science 303, 1652 (2004).

${ }^{2}$ A. Arranz and C. Palacio, Thin Solid Films 317, 55 (1998).

${ }^{3}$ E. McCafferty, Corros. Sci. 47, 1765 (2005).

${ }^{4}$ A. Arranz and C. Palacio, Langmuir 18, 1695 (2002).

${ }^{5}$ S. K. R. S. Sankaranarayanan and S. Ramanathan, Phys. Rev. B 78, 085420 (2008).

${ }^{6}$ M. Hirsimaeki, M. Lampimaeki, K. Lahtonen, I. Chorkendorff, and M. Valden, Surf. Sci. 583, 157 (2005).

${ }^{7}$ V. Maurice, G. Despert, S. Zanna, P. Josso, M.-P. Bacos, and P. Marcus, Surf. Sci. 596, 61 (2005).

${ }^{8}$ M. Paljević and M. Tudja, Corros. Sci. 50, 818 (2008).

${ }^{9}$ J. Klöwer, U. Brill, and U. Heubner, Intermetallics 7, 1183 (1999).

${ }^{10}$ D. E. Mencer, Jr., D. L. Cocke, and C. Yoon, Surf. Interface Anal. 17, 31 (1991).

${ }^{11}$ C. L. Chang, M. H. Engelhard, and S. Ramanathan, Appl. Phys. Lett. 92, 263103 (2008).

${ }^{12}$ I. Popova, V. Zhukov, and J. T. Yates, Jr., Phys. Rev. Lett. 89, 276101 (2002).

${ }^{13}$ S. K. R. S. Sankaranarayanan, E. Kaxiras, and S. Ramanathan,
Phys. Rev. Lett. 102, 095504 (2009).

${ }^{14}$ E. T. Byram, T. A. Chubb, and H. Friedman, Phys. Rev. 98, 1594 (1955).

${ }^{15}$ C. L. Chang and S. Ramanathan, J. Electrochem. Soc. 154, G160 (2007).

${ }^{16}$ M. Tsuchiya, S. Sankaranarayanan, and S. Ramanathan, Prog. Mater. Sci. 54, 981 (2009).

${ }^{17}$ N. Cabrera and N. F. Mott, Rep. Prog. Phys. 12, 163 (1949).

${ }^{18}$ Y. Motoyama, K. Kurosawa, and A. Yokotani, Electron. Commun. Jpn., Part 2: Electron. 88, 36 (2005).

${ }^{19}$ I. I. Liaw and I. W. Boyd, The Development and Application of UV Excimer Lamps in Nanofabrication (Springer, Netherlands, 2007).

${ }^{20}$ P. P. Ewald, Ann. Phys. 369, 253 (1921).

${ }^{21}$ D. J. Evans and B. L. Holian, J. Chem. Phys. 83, 4069 (1985).

${ }^{22}$ M. P. Allen and D. J. Tildesley, Computer Simulation of Liquids (Clarendon, Oxford, 1987).

${ }^{23}$ S. Ahn, H. Kwon, and D. D. Macdonald, J. Electrochem. Soc. 152, B482 (2005).

${ }^{24}$ E. Sikora and D. D. Macdonald, Electrochim. Acta 48, 69 (2002).

${ }^{25}$ V. Maurice, L. H. Klein, and P. Marcus, Surf. Interface Anal. 34, 
139 (2002).

${ }^{26}$ A. Bouzoubaa, B. Diawara, V. Maurice, C. Minot, and P. Marcus, Corros. Sci. 51, 941 (2009).

${ }^{27}$ C. L. Chang, S. K. R. S. Sankaranarayanan, M. Engelhard, V. Shutthanandan, and S. Ramanathan, J. Phys. Chem. C 113, 3502 (2009).

${ }^{28}$ A. Kuznetsova, I. Popova, V. Zhukov, J. T. Yates, G. Zhou, J. C. Yang, and X. Chen, J. Vac. Sci. Technol. A 19, 1971 (2001).

${ }^{29}$ G. van der Laan, C. Westra, C. Haas, and G. A. Sawatzky, Phys. Rev. B 23, 4369 (1981).

${ }^{30}$ V. Biju, MRS Bull. 42, 791 (2007).

${ }^{31}$ G. K. Wertheim and S. Hufner, Phys. Rev. Lett. 28, 1028 (1972).

${ }^{32}$ M. A. van Veenendaal and G. A. Sawatzky, Phys. Rev. Lett. 70, 2459 (1993).

${ }^{33}$ A. R. Kortan and R. L. Park, Phys. Rev. B 23, 6340 (1981).

${ }^{34}$ W. Low, Phys. Rev. 109, 247 (1958).

${ }^{35}$ R. Newman and R. M. Chrenko, Phys. Rev. 114, 1507 (1959).

${ }^{36}$ M. Tomellini, J. Chem. Soc., Faraday Trans. 1 84, 3501 (1988).

${ }^{37}$ A. Galtayries and J. Grimblot, J. Electron Spectrosc. Relat. Phenom. 98-99, 267 (1999).

${ }^{38}$ B. P. Payne, A. P. Grosvenor, M. C. Biesinger, B. A. Kobe, and N. S. McIntyre, Surf. Interface Anal. 39, 582 (2007).

${ }^{39}$ P. R. Norton, R. L. Tapping, and J. W. Goodale, Surf. Sci. 65, 13 (1977).

${ }^{40}$ N. Kitakatsu, V. Maurice, C. Hinnen, and P. Marcus, Surf. Sci. 407, 36 (1998).
${ }^{41}$ J. G. Chen, B. Fruhberger, and M. L. Colaianni, J. Vac. Sci. Technol. A 14, 1668 (1996).

${ }^{42}$ M. H. Cho, D. W. Moon, S. A. Park, Y. K. Kim, K. Jeong, S. K. Kang, D.-H. Ko, S. J. Doh, J. H. Lee, and N. I. Lee, Appl. Phys. Lett. 84, 5243 (2004).

${ }^{43}$ X. W. Zhou, H. N. G. Wadley, J.-S. Filhol, and M. N. Neurock, Phys. Rev. B 69, 035402 (2004).

${ }^{44}$ A. J. Bourdillon, R. G. Jones, and A. J. Forty, Philos. Mag. A 49, 341 (1984).

${ }^{45}$ L. S. Caputi, S. L. Jiang, A. Amoddeo, and R. Tucci, Phys. Rev. B 41, 8513 (1990).

${ }^{46}$ R. M. Jaeger, H. Kuhlenbeck, H. J. Freund, M. Wuttig, W. Hoffmann, R. Franchy, and H. Ibach, Surf. Sci. 259, 235 (1991).

${ }^{47}$ R. Franchy, J. Masuch, and P. Gassmann, Appl. Surf. Sci. 93, 317 (1996).

${ }^{48}$ M. W. Finnis, A. Y. Lozovoi, and A. Alavi, Annu. Rev. Mater. Res. 35, 167 (2005).

${ }^{49}$ K. R. Lawless, Rep. Prog. Phys. 37, 231 (1974).

${ }^{50}$ L. Jeurgens, A. Lyapin, and E. Mittemeijer, Acta Mater. 53, 4871 (2005).

${ }^{51}$ L. Jeurgens, A. Lyapin, and E. Mittemeijer, Surf. Interface Anal. 38, 727 (2006).

${ }^{52}$ V. Maurice, G. Despert, S. Zanna, M.-P. Bacos, and P. Marcus, Nature Mater. 3, 687 (2004).

${ }^{53}$ B. MacDougall and M. Cohen, J. Electrochem. Soc. 123, 191 (1976). 